\title{
OPTIMIZED SOLID-STATE BIPOLAR MARX MODULADOR WITH RESONANT TYPE DROOP COMPENSATION*
}

\author{
H. Canacsinh ${ }^{1,3, \xi}$, F. A. Silva ${ }^{2,3}$, L. M. Redondo ${ }^{1}$, L. Rocha ${ }^{1,3}$, V. Silva ${ }^{1}$, J. Mendes ${ }^{1}$, \\ H. Bermaki ${ }^{1}$, A. Semmak ${ }^{1}$ \\ ${ }^{1}$ Instituto Superior de Engenharia de Lisboa, GIAAPP, Instituto Politécnico de Lisboa, Portugal \\ ${ }^{2}$ Instituto Superior Técnico, Universidade de Lisboa, Portugal \\ ${ }^{3}$ INESC-ID, Portugal
}

\begin{abstract}
In this paper a voltage droop compensation based on a resonant circuit is proposed for the optimized solid-state bipolar Marx modulator. Keeping the modularity characteristics and the circuit topology, one auxiliary resonant stage was added to the existing Marx stages. The compensation concept consists of adding the auxiliary voltage to the output positive or negative pulse for voltage droop compensation. Simulation results are presented for five stages Marx circuit, 10\% voltage droop, using $800 \mathrm{~V}$ per stage, $100 \mu$ s pulse duration at $50 \mathrm{~Hz}$ frequency.
\end{abstract}

\section{I.INTRODUCTION}

Nowadays there are several topologies based on the Marx concept using power semiconductors devices as switches that can generate unipolar and bipolar high voltage pulses. In some industrial applications, such as water decontamination or liquid food processing, the use of bipolar pulses instead of unipolar pulses, has demonstrated an enhanced final product or industrial process $[1,2]$. Generally, high voltage bipolar modulators require additional switches, which may allow fault tolerance capability but requires a complex triggering circuit [3-7]. Alternatively, optimized bipolar topologies [8-10] using reduced number of semiconductors per cell may create an additional stress in some stage semiconductors due to their use in more than one operating mode, which increases their losses. Thus, beyond the semiconductors characteristics, the design of the Marx modulator must consider the pulse energy and the required pulse voltage decay to determine the capacitance of the capacitors. Considering this last point, in various conditions, the determined capacitance values may be too high for affordable designs of compact Marx modulators. For this reason, voltage droop compensation techniques must be considered [11-13].
Considering the optimized solid-state bipolar Marx modulator topology [10], a voltage droop compensation technique based in resonant circuit is proposed in this paper, as shown in Fig. 1.

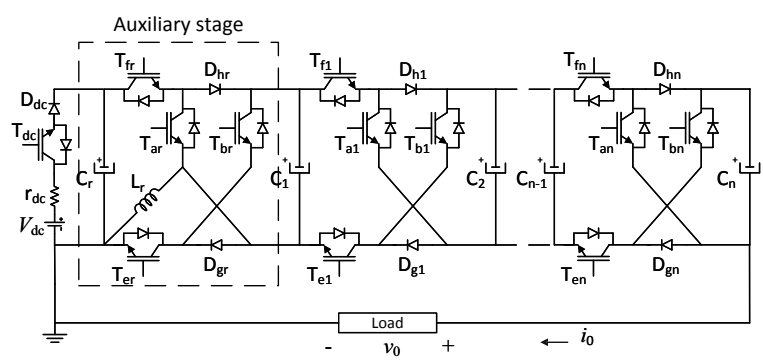

Figure 1. Schematic drawing of the optimized bipolar solid-state Marx modulator with $n$ stages for bipolar/unipolar pulse generation and with resonant type voltage droop compensation.

In the Marx circuit of Fig. 1, one auxiliary compensation stage was added to the Marx stages with the aim of compensating the voltage droop of negative or positive pulses.

\section{CIRCUIT OPERATION}

The first operating mode of Fig. 1 circuit consists on charging the capacitors $C_{r}$ and $C_{i}$ through the switches $\mathrm{T}_{\mathrm{dc}}, \mathrm{T}_{\mathrm{fr}}, \mathrm{T}_{\mathrm{fi}}, \mathrm{T}_{\mathrm{ei}}$ and $\mathrm{T}_{\mathrm{er}}$ (with $i$ as an index of the stage number) in ON state, as represented in Fig. 2, with the DC power supply voltage, $V_{\mathrm{dc}}$.

The second operating mode consists in connecting the capacitors in series to apply the sum of their voltage into the load. However, the generation of high voltage pulse with resonant type compensation requires the beginning of the resonance process before applying the pulse into the load.

\footnotetext{
* This work was supported by national funds through Fundação para a Ciência e a Tecnologia (FCT) with reference UID/CEC/50021/2013, and through Instituto Politécnico Lisboa (IPL) with reference MBOCDTI/710046/2016.

$\xi$ email: hic@deea.isel.ipl.pt
} 


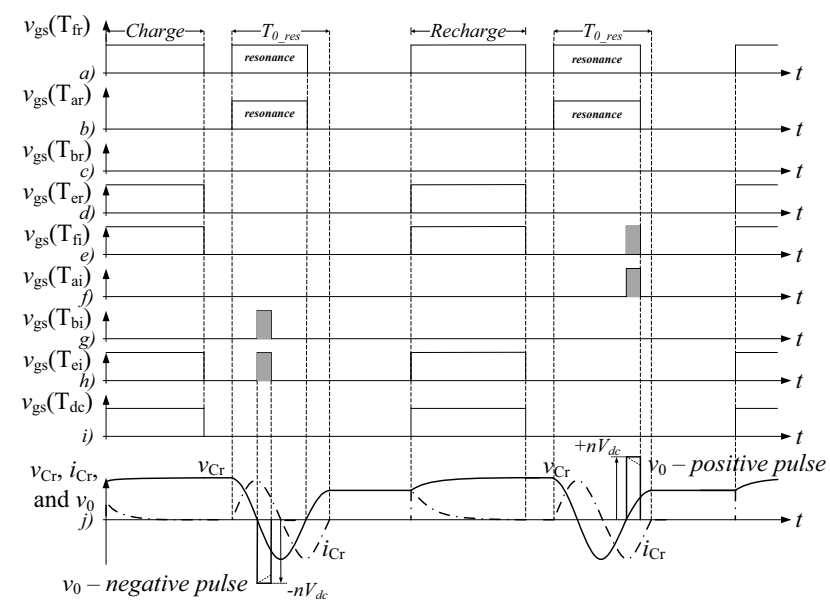

Figure 2. Theoretical wave forms for the operation of the solidstate Marx modulator of Fig. 1, considering a resistive load. Drive signal of semiconductors: a) $\mathrm{T}_{\mathrm{fr}} ; \mathrm{b}$ ) $\mathrm{T}_{\mathrm{ar}}$; c) $\mathrm{T}_{\mathrm{br}}$; d) $\mathrm{T}_{\mathrm{er}} ; \mathrm{e}$ $\mathrm{T}_{\mathrm{fi}}$; f) $\mathrm{T}_{\mathrm{ai}}$; g) $\mathrm{T}_{\mathrm{bi}}$; h) $\mathrm{T}_{\mathrm{ei}}$; i) $\left.\mathrm{T}_{\mathrm{dc}}, \mathrm{j}\right) v_{\mathrm{Cr}}, i_{\mathrm{Cr}}$ and output $v_{0}$ voltage.

The resonance process under the auxiliary stage can be started by turning ON switches $\mathrm{T}_{\text {fr }}$ and $\mathrm{T}_{\text {ar }}$ (Fig. 2 a) and b)), as represented in Fig. 2 j).

For positive pulse generation with droop compensation, switches $T_{\text {fi }}$ and $T_{\text {ai }}$ (Fig. 2 e) and f)) should be turned ON when the waveform of the voltage of the resonance capacitor $\mathrm{C}_{\mathrm{r}}$ crosses the reference coming from negative values, as shown in Fig. $2 \mathrm{j}$ ).

After the positive pulse, all switches $\left(\mathrm{T}_{\mathrm{fi}}, \mathrm{T}_{\mathrm{ai}}, \mathrm{T}_{\mathrm{fr}}\right.$ and $\mathrm{T}_{\mathrm{ar}}$ ) can be turned OFF.

Considering the negative pulse operating mode with compensation, the process is similar to the positive pulse. Thus, the resonance process under the auxiliary stage is started by triggering $O N$ switches $T_{f r}$ and $T_{a r}$. The negative pulse with compensation can be generated (by triggering $\mathrm{ON}$ switches $\mathrm{T}_{\mathrm{bi}}$ and $\mathrm{T}_{\mathrm{ei}}-$ Fig. 2 g) and $\mathrm{h}$ )) when the waveform of the voltage of the resonant capacitor, $v_{\mathrm{Cr}}$, crosses the reference coming from positive values, as shown in Fig. 2 j). Within this situation, switches $T_{\text {fr }}$ and $T_{\text {ar }}$ of the auxiliary stage are turned OFF after the waveform of the current in the inductor $\mathrm{L}_{\mathrm{r}}, i_{\mathrm{Cr}}$, has inverted its polarity, to allow the transfer of the remaining energy from the inductor $\mathrm{L}_{\mathrm{r}}$ back to the capacitor $\mathrm{C}_{\mathrm{r}}$.

\section{III.SIMULATION RESULTS}

The circuit of Fig. 1, with five stages was simulated in LTspice software. The simulated circuit was operated with $V_{\mathrm{dc}}=800 \mathrm{~V}$, applying bipolar pulses with $1 \%$ duty cycle at $50 \mathrm{~Hz}$ repetition rate, into an $850 \Omega$ resistive load, with $10 \%$ voltage droop compensation.

Fig. 3 shows the simulated results for the load voltage $v_{0}$ with $10 \%$ voltage droop at the end of the positive and

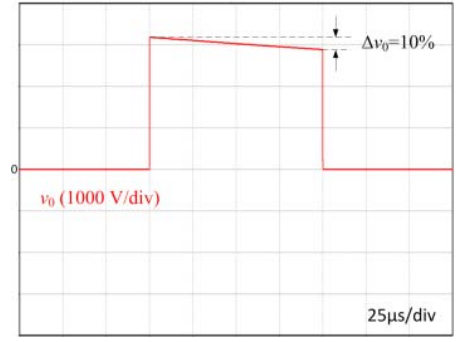

(a)

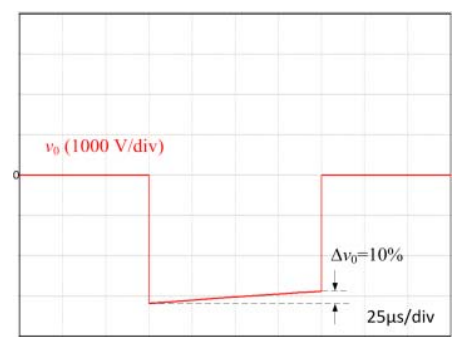

(b)

Figure 3. Simulation results for the output voltage of the circuit of Fig. 1 into a resistive load, without compensation and $10 \%$ voltage droop at the end of the positive (a) and negative (b) pulse. The scales are $25 \mu \mathrm{s} / \mathrm{div}$ (horizontal) and $1 \mathrm{kV} / \mathrm{div}$ (vertical).

negative pulses.

In Fig. 4 simulated results are shown for the voltage and current waveforms in capacitor $\mathrm{C}_{\mathrm{r}}$ and inductor $\mathrm{L}_{\mathrm{r}}$,

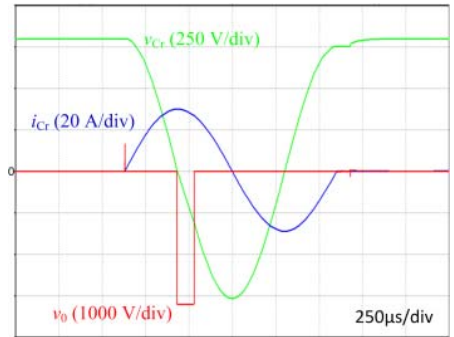

(a)

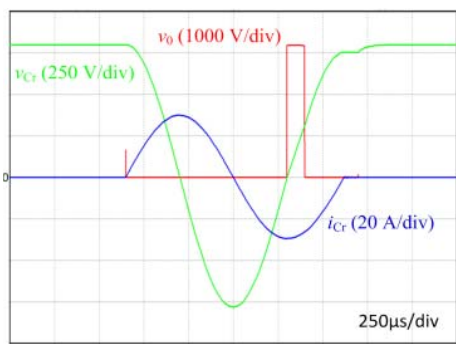

(b)

Figure 4. Simulation results for the capacitor $\mathrm{C}_{\mathrm{r}}$ voltage, $v_{\mathrm{Cr}}$, current $i_{\mathrm{Lr}}$ in inductor $\mathrm{L}_{\mathrm{r}}$, and the output voltage, $v_{0}$, of the circuit of Fig. 1, with compensation, for positive (a) and negative (b) pulse. The scales are $250 \mu \mathrm{s} /$ div (horizontal) and $250 \mathrm{~V} /$ div (vertical) and $1 \mathrm{kV} /$ div (vertical).

respectively and the load voltage $v_{0}$, with compensation. 
The positive and negative pulses occur during zero crossing of the capacitor $\mathrm{C}_{\mathrm{r}}$ resonant voltage.

In Fig. 5 a) and b) it is shown the simulation results of the output negative and positive pulse voltage with voltage droop compensation with zoomed horizontal scale.

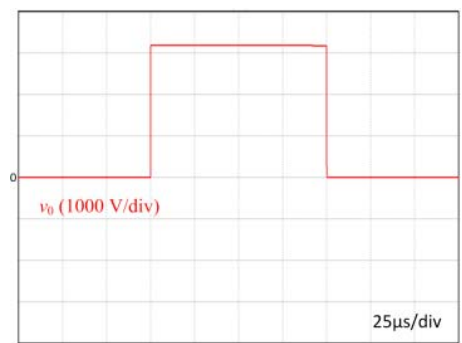

(a)

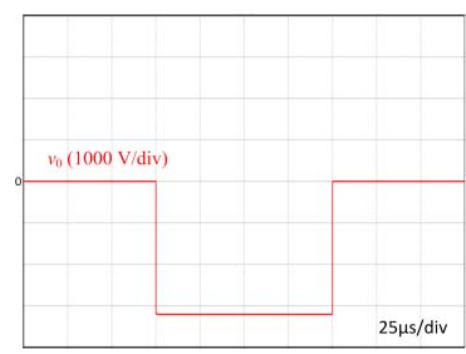

(b)

Figure 5. Simulation results of the obtained output (a) positive and (b) negative pulse voltage with resonant compensation with zoomed horizontal scale, $25 \mu \mathrm{s} / \mathrm{div}$ (horizontal) and $1 \mathrm{kV} / \mathrm{div}$ (vertical).

\section{IV.SUMMARY}

A new design scheme for the voltage droop compensation based on resonant circuit was proposed for the optimized solid-state bipolar Marx modulator of Fig. 1. With the goal of maintaining the modularity and the topology of the circuit, an auxiliary compensation stage with inductor was added to the existing Marx stages, which compensates the voltage droop of the output bipolar pulses.

The simulations results showed 4 stages Marx circuit and one auxiliary compensation stage, using $800 \mathrm{~V}$ per stage, operating with $50 \mathrm{~Hz}$ repetition rate, giving $3.2 \mathrm{kV}$ bipolar pulses with the capability to compensate $10 \%$ voltage droop at the end of the negative and positive pulses.

\section{REFERENCES}

[1] Y. Xu, R. Zhang, C. Zhang, Z. Li, Z. Guan and L. Wang, "Bipolar pulsed discharge in the Gas-liquid-solid mixture and its application for water treatment", IEEE 9th International Conference on the Properties and Applications of Dielectric Materials, 19-23 July 2009, pp. $579-582$.

[2] Kinetics of Microbial Inactivation for Alternative Food Processing Technologies - Pulsed Electric Fields, A report of the Institute of Food Technologists for the Food and Drug Administration of the U.S. Department of Health and Human Services submitted March 29, 2000 revised June 2.

[3] L. Redondo, E. Margato, J. Fernando Silva, A new method to build a High Voltage Pulse Supply using only semiconductor switches for plasma immersion ion implantation, Surface \& Coatings Technology Journal, vol.136/1-3, pp 51-54, 2001.

[4] L.M. Redondo, J. Fernando Silva, Elmano Margato, P. Tavares, All Silicon Marx-bank topology for highvoltage, high-frequency rectangular pulses, PESC 2005 Proc., Junho, Recife, Brasil, pp 1170-1174, 2005.

[5] L. M. Redondo; H. Canacsinh; J. Fernando Silva: "Generalized Solid-state Marx Modulator Topology", in IEEE Transactions on Dielectrics and Electrical Insulation, Vol. 16, No. 4, 2009, pp. 1037-1042.

[6] Gao, Lan; Wang, Dongdong; Qiu, Jian; Liu, Kefu: "All-Solid-State Pulse Adder with Bipolar High Voltage Fast Narrow Pulses Output," in IEEE Transactions on Dielectrics and Electrical Insulation, Vol. 18, No. 3, pp. 775-782, June 2011.

[7] J. P. M. Mendes, H. Canacsinh, L. M. Redondo and José O. Rossi: "Solid-State Marx Modulator with Blumlein Stack for Bipolar Pulse Generation" in IEEE Transactions on Dielectrics and Electrical Insulation, Vol. 18, No. 4, August 2011, pp. 1199 - 1204.

[8] Tastekin, D.; Blank, F.; Lunk, A.; Roth-Stielow, J.: "Power supply with bipolar pulsed output voltage and high repetition rate based on a solid state Marx topology", Pulsed Power Conference, June 2011, pp. 1377 - 1381.

[9] Sakamoto, T.; Nami, A.; Akiyama, M.; Akiyama, H.: "A Repetitive Solid State Marx-Type Pulsed Power Generator Using Multistage Switch-Capacitor Cells", IEEE Transactions on Plasma Science, Vol. 40, No. 10, pp. 2316 - 2321, October 2012.

[10] H. Canacsinh, L. M. Redondo and J. Fernando Silva, "Marx type solid-state bipolar modulator topologies: performance comparison", IEEE Transactions Plasma Science, 2012.

[11] Pfeffer, H.; Bartelson, L.; Bourkland, K.; Jensen, C.; Kerns, Q.; Prieto, P.; Saewert, G.; Wolff, D.: "A Long Pulse Modulator For Reduced Size and Cost", TwentyFirst International-Power-Modulator-Symposium, 1994. 
[12] Burkhart, Craig P.; Beukers, T.; Kemp, Mark A.; Larsen, Raymond S.; Macken, K. J P; Nguyen, Minh N.; Olsen, Jeff J.; Tang, Tao: "ILC Marx Modulator Development Program Status", IEEE Pulsed-PowerConference, 2009.

[13] Hiren Canacsinh, Luís M. Redondo, J. Fernando Silva, Beatriz Borges: "Voltage Droop Compensation Based on Resonant Circuit for Generalized High Voltage Solid-State Marx Modulator", in IEEE Applied Power Electronics Conference and Exposition (APEC), Long Beach, California, USA, 20-24 March, 2016. 